\title{
ENGLISH LITERATURE INSTRUCTORS' BELIEFS AND ACTUAL PRACTICES OF INTEGRATING WEB APPLICATIONS IN HA'IL UNIVERSITY
}

\author{
Khatmeh Suleiman Elgoudman ${ }^{{ }^{*}}$ \\ University Sultan Zainal Abidin, Faculty of Languages and Communication. \\ *Corresponding author: K.elgoudman@uoh.edu.sa \\ Kamariah Yunus ${ }^{2}$ \\ University Sultan Zainal Abidin, Faculty of Languages and Communication. \\ (Email: kamariah@unisza.edu.my)
}

Received date: $15-07-2019$

Revised date: 01-08-2019

Accepted date: 10-10-2019

Published date: 05-12-2019

To cite this document: Elgoudman, K. S., \& Yunus, K. (2019). English Literature Instructors' Beliefs and Actual Practices of Integrating Web Applications in Ha'il Universiry. International Journal of Humanities, Philosophy and Language, 2(8), 28-50.

DOI: $10.35631 /$ ijhpl.28003

\begin{abstract}
This study purports to explore differences and similarities between literature instructors' beliefs and actual practices of integrating Web applications in literature courses in Ha'il University. This study was designed as a descriptive case-study triangulating several data collection methods such as semi-structured interviews and observation. The data of the interviews and observation were analysed in themes. The results showed that a majority of instructors' beliefs aligned well with their practices about integrating Web applications with teaching literature while one participant's beliefs conflicted with her teaching practices. Result also supported the argument that instructor belief plays an important role in instructional decision making in the teaching practice while sometimes differed with their classroom practice. Results also revealed that the actual Web applications usage found in the four cases demonstrated positive result for the integration of Web applications. This provides evidence to support previous research results about the benefits that Web applications have in possibly connecting informal learning to the formal learning environment. On the other hand, although four individual instructors' actual use of Web applications differed from case to case, they all believed that there were many benefits as well as challenges when integrating Web applications in literature courses. Furthermore, the results demonstrated an increasing usage trend among the four individual participants based on the estimated percentage of Web applications usage in their literature courses. Nonetheless, four participants in this study seemed to only bring out a few aspects of Web applications' potential. To make the best of Web applications, more research is needed in identifying best practices of various Web applications in teaching literature and explaining complicated instructors' beliefs about the effectiveness of Web applications in teaching literature.
\end{abstract}

Keywords: Instructors' Beliefs, Web Applications, Teaching Literature 


\section{Introduction}

Recently, technology has improved from analog electronic and mechanical devices to the digital technology available today, referred to as the "Digital Revolution" (Delgado, Wardlow, McKnight, \& O'Malley, 2015, p. 397). Researchers have stated that students born during the digital era have experienced exceptional developments regarding communication technology. Among the most widely used technological social interaction tools are Facebook and Twitter (Salmon, Ross, Pechenkina, \& Chase, 2015).

The increasing use of Web 2.0 applications attracts researchers to focus on them in their studies. Many researchers find that younger people dominate Web 2.0 applications. Cavarlee and Webb (2008) find that nearly 85\% of users of MySpace are 30 years of age or younger, and the astonishing fact is that the highest number of users are in their 20s. Another study finds that college students between the ages of 18 and 24 use social media more frequently than other age groups, and Facebook and YouTube were the two most commonly used networking sites (Poelhuber \& Anderson, 2011).

In Saudi Arabia, Ministry of Education tries to provide all the modern technology in English language teaching classrooms. However, unless teachers utilize it properly, the teaching of the English language cannot be fruitful. Teachers of English prefer rote learning, following the grammar translation method, or any other methods that are teacher-centred, and which rely heavily on L1. Teachers need to think of new methodologies for classroom interaction, and these methods will have to be based on techniques which will enable the students to enjoy their English language class. As recommended by Alrashidi, \& Phan (2015) the role of educational technology in the language classroom is very crucial. Along the same lines, the current study has been conducted to explore literature instructors' experience in using Web 2.0 application in teaching literature to Ha'il University students.

\section{Problem Statement}

In the light of technological development and the adoption of diverse technologies in the field of education, the student has become an active element in learning through student-centred learning environments. Universities are striving to keep up with the technological developments and the employment of modern trends in the educational process through the gradual integration of interactive learning methods or strategies. The specific problem is that many instructors do not understand the many advantages that Web 2.0 technologies can bring to their teaching, nor the kinds of problems they may run into when using them, and, most importantly, how to use these tools effectively in their classrooms (Bower, 2015; Daher \& Lazarevic, 2014). Undoubtedly, Web 2.0 technology integration is of high importance for 21 st-century teaching and learning. The use of Web 2.0 tools can provide needed support and practice for English students (Gustad, 2014; Larabee et al., 2014; Liu et al., 2014). Web 2.0 technology integration in language teaching is known to improve academic language acquisition (Green et al., 2014; Gustad, 2014). Research on Web 2.0 technology integration has indicated improvements in student learning with the use of Web 2.0 tools (Larabee et al., 2014). Despite all the promising benefits stated above, the integration of Web 2.0 technologies in teaching is still not as prevalent as it should be (Toetenel, 2014). Opportunities for students to experience technology in the classroom is at the discretion of the teacher, whose technological, pedagogical, and content knowledge influences those decisions (Celik et al., 2014; Liu et al., 2014). 
Recently, there has been much discussion about the integration of Web 2.0 technologies into language education (Greenhow \& Lewin 2016; Dron \& Anderson, 2014). However, little attention has been paid to the experiences of language educators, those who adopt Web 2.0 for educational purposes. Tay et al. (2015) state that there is a gap between what is known about investments in technology in the educational setting and the use of technology for educational purposes in educational organizations. As a result, the literature that is specifically about the use of Web 2.0 technologies in higher education settings, with the focus on literature courses, is insufficient. There has been no clear indication of instructors' experience with the integration of Web 2.0 tools and technology, specifically in literature courses.

More specifically, in Saudi Arabia, rote memorization is considered the chief learning method, so students are expected to reproduce correct answers exactly as stated in the book or given by the teacher if they are to pass their exams (Matson, 2016). Therefore, students memorize answers and paragraphs sometimes without fully comprehending them (Alkubaidi, 2014). Similarly, Other studies such as Alhamdi (2014), Al-Asmari \& Khan (2014), Alharbi (2015) and Sofi (2015) discuss list of factors that affect the educational process in teaching English literature in Saudi universities such as reliance on rote learning and memorization, dependence on high-stakes testing, outdated curricula and methodologies, insufficient support systems, and the rarity of qualified teachers. Al-Asmari \& Khan (2014) argue for the need to go beyond the traditional teaching of English in KSA. Alharbi (2015) too attributes the low proficiency of Saudi students in English communication to ineffective teaching methods (for example, using Arabic when teaching English and keeping the classroom teacher-centered. To overcome these obstacles, Alharbi proposes a reform of specific policies of the Ministry of Education and Higher Education and the employment of contemporary approaches to teaching which emphasize skills in problem solving and critical thinking. Sofi (2015) assumes that learning by rote and lectures are methods still used in Saudi Arabia because English teachers are not well trained for the job. In addition to that, Al-Zyoud \& Muhammad (2012, p.4) state that "Students in Saudi Arabia have been shown to perform below average in literature -novel courses. The problem is not only with students but also with teachers, especially teachers in Saudi Arabia. Teachers have difficulty in conveying literature/novels to students". The survey conducted by the researchers in the English Department, Al-Majma'ah College, shows that all English professors and lecturers need a new methodology that explains the material of the novel class to students in a proper manner that increases their comprehension of novels.

\section{Research Objective}

The following is the main objective of the research:

To explore differences and similarities between English literature instructors' beliefs and actual practices of integrating Web applications.

\section{Research Questions}

The study has been guided by the following question:

\section{Question One}

What differences and similarities can be identified between instructors' beliefs and actual practices of integrating Web applications in teaching literature? 


\section{Significance of the Study}

There has been a lack of information in the professional literature dealing with the adoption of Web2.0 in teaching literature courses. Also, there is a critical need for educational research regarding the implementation of web applications into literature courses in Saudi higher education. Therefore, this study is significant as it has the potential to provide a better understanding of English literature instructors' experiences, especially as there is a lack of studies which focus on the teaching of literature, specifically.

Furthermore, little research has been done in conjunction with literature pedagogy. Because the use of Web 2.0 in teaching literature is still in its conceptual stage, no concrete measure of its effectiveness exists, nor are there any universally recognized guidelines which potential Web 2.0 users can follow with confidence. If literature teachers are to embrace the learning patterns of 21 st-century students, then the development of such guidelines is crucial. Faculty members must learn not only how to use Web 2.0 technologies, but also how to successfully infuse Web 2.0 technologies into their curriculums to improve learning. The results are expected to empower and enable the faculty members to productively utilize technology within their curricula and classrooms, thus providing a state- of- the art experience for the student community at institutions of higher education.

It is hoped that the present study may enlighten university administrators and instructors in their decision making on how to integrate Web 2.0 technologies to meet the academic and social needs of their students. In other words, this study is needed because the results would signify forward movement in the understanding of the use of Web 2.0 technologies to support English language instructors as well as students in the classroom setting. Thus, researcher aims to address the gap in research regarding the implementation of Web 2.0 technologies by English literature instructors.

\section{Literature Review}

There are 3 points will be discussed in literature review. Definitions of Web applications, relationship between instructors' beliefs and integration of Web 2.0 applications and Web 2.0 and higher education.

\section{Definitions of Web Applications}

A comprehensive and detailed discussion of all types and generations of Web is beyond the scope of this study. A brief and precise information about the term will be given. The Internet (Web 1.0) is defined as a system of computer networks that operate worldwide using a standard set of communications protocols and enables existing users to communicate in a minimalistic way (Pellegrino \& Hilton, 2012). In contrast to Web 1.0, which refers to the original informational web, Web 2.0 refers to the social web. It is a grouping of newer generation of social technologies, whose users are actively involved in communicating and collaborating with each other as they build connections and communities across the web (Tim O'Reilly,2012). In addition to that, Song (2010) provides a comprehensive definition: "Web 2.0 represents many things: it is a set of different techniques, a new generation of software, and a new set of business models, which all facilitate new social and expressive practices for contemporary Internet users" (p.269).

Similarly, Imperatore (2009) compares the two generations of the Web (Web 1.0 \& Web 2.0) and states that with the first generation (Web 1.0), users are only receivers of information due to the nature of one-way communication, whilst Web 2.0 gives them the ability to control the 
information, share thoughts and experiences, and comment on others' thoughts and experiences. Rudd \& Walker (2010) add: "Web 2.0 technologies allow for informal discussions, seeking information, sharing resources and community building, all on one familiar device" (p. 17). Web 2.0 changed the Internet user's role from reading on Web 1.0 to reading and writing on the Web (Coutinho, 2009). Semantic Web, or Web 3.0, has now emerged, with more sophisticated systems able to collect, link, and analyze data from different sources. Aghaei, Nematbakhsh, and Farsani (2012, p.5)) define Web 3.0 as "a web that can demonstrate things in an approach which computers can understand. The main important purpose of the semantic web is to make the web readable by machines and not only by humans". The difference between 3.0 and Web 2.0, as Aghaei et al. (2012) believe, is that Web 3.0 focuses on the data links rather than the content created by users. In other words, "Web 2.0 is seen as enabling user participation while Web 3.0 is seen as [triggering] users" cooperation" (Barassi \& Treré, 2012, p. 270). However, what matters for teachers is the power of Web applications as creative teaching and learning tools.

Though definitions vary, there is an agreement that sharing, production, interactivity, along with connectivity are among the distinctive properties of Web 2.0 tools, and these features support the users to move from passive consumption of information to active contribution through sharing and interacting with other users.

\section{Relationship Between Instructors' Beliefs and Integration of Web 2.0 Applications}

Beliefs have a key role in language teaching (Li, 2012) Teacher beliefs have been defined as "suppositions or commitments and are based on evaluation and judgment" (Meirink, Meijer, Verloop, \& Bergen, 2009b, p. 90). Amiryousefi (2015) asserts that what teachers do is identified by their beliefs. Also, Abdi and Asadi (2015) express that teachers' beliefs about teaching and learning are affected by their own experiences as learners and are established when they go to university, act as a filter through which teachers explain new information, exert a deep effect on teachers' instructional practices, are, not always indicated in what they do in the classroom, have a great impact on their teaching decisions, and greatly affect what and how they learn during language teaching.

Moreover, Saroyan and Amundsen (2001) even argue that if teachers conscientiously tried to align their beliefs about teaching with their actual teaching practice, instructional goals were more likely to be accomplished. Norton et al. (2005) argue that teachers can benefit from reflecting on their beliefs and underlying conceptions of teaching and learning. On the other hand, teachers' beliefs towards teaching, might be held as both "ideal" conceptions and "working" conceptions of teaching, were not necessarily the same as their intentions. Other researchers, such as Rienties, Brouwer, and Lygo-Baker (2013), also find that teachers had significantly different beliefs and intentions, indicating that their own ideal conceptions of teaching differed from those in practice.

Instructors, in general, have mixed feelings about using Web 2.0 applications for teaching purposes. While agreeing the benefits of using web 2.0 applications for personal uses, faculty members have different perceptions about the value of using web 2.0 applications as a professional tool for both in and outside of classroom (Moran, Seaman, \& Tinti-Kane ,2012) Instructors' use of Web 2.0 applications changed dramatically over time. In 2009, the Faculty Survey of Student Engagement (FSSE, 2010) conducted a national survey over 4,600 faculty members from 50 United States colleges and universities. Results showed that over $80 \%$ of the surveyed faculty members did not know or never used Web 2.0 applications such as blogs, wikis, Google docs, and video conferencing tools. However, Moran et al. (2012) found 
that almost all higher education teaching faculty are aware of the major Web 2.0 applications; more than $75 \%$ visited a social media site within the past month for their personal use; and nearly $50 \%$ posted content. More importantly, over $90 \%$ of all faculty members are using Web 2.0 applications in courses they're teaching or for their professional careers outside the classroom. Nearly $65 \%$ of all faculty members have used Web 2.0 applications during a class session.

Although it is difficult to find empirical studies exploring instructors' beliefs about using Web 2.0 applications in teaching, many researchers have examined teachers' beliefs with a broader term "technology" (Kim, Kim, Lee, Spector, \& Demeester, 2013). Ertmer (2005) argued that for lasting successful integration of technology in education, it is necessary to change teachers' beliefs about the implementation of technology in education towards a more student-centred orientation. Furthermore, Oda (2011) suggested that in order for technology to be integrated effectively in English language classrooms, professional development programs needed to focus on teachers' beliefs about teaching and learning and beliefs about teaching and technology.

\section{Web 2.0 and Higher Education}

Higher education institutions realize that in order to remain competitive and relevant in the eyes of their end users, they need to be proactive and up-to-date with the technological evolution. The number of institutions integrating Web 2.0 in learning have increased, harvesting the benefits of Web 2.0 tools by incorporating interactive and collaborative activities among students based on participation and collaboration and social networks (Hicks \& Graber, 2010; Tian, Yu, Vogel \& Kwok, 2011). Early articles from Downes (2004; 2005; 2005b) and Farmer (2005) helped to pave the way towards the understanding of Web 2.0 in the area of learning and teaching. These early studies suggest that the use of Web 2.0 tools in learning is happening and yet it is not fully understood.

J. Gikas and M. Grant (2013) explore teaching and learning using Web 2.0 applications. Their qualitative research study focuses on students from three universities across the US. Data were collected through student focus group interviews. Two themes emerged: (a) advantages of Web 2.0 applications for student learning and (b) frustrations from learning with mobile computing devices. Moreover, the use of Web 2.0 applications creat opportunities for interaction and collaboration, as well as allowed students to engage in content creation and communication.

M. A. Kenny (2015) suggests why to use Web 2.0 applications in language learning / teaching. The pedagogical arguments include authentic and independent learning, high motivation and fun, meaningful interaction (peer-peer, student-instructor), vast resources of authentic audio and video materials. Some ways of using Web 2.0 applications like Facebook, Twitter, YouTube, or blogs are described.

Web 2.0 technology has marked an opportunity to revolutionize learning by offering more options for classroom collaboration needs (Merchant, 2012). Brown (2012, p. 51) states that Web 2.0 technologies "can provide students with an arena in which to become collaborators in the generation of knowledge, rather than passive recipients of knowledge". Furthermore, Mason \& Rennie (2013) argue that, when educators integrate Web 2.0 tools in the classroom, they can create a more student-centered environment, in comparison with the traditional online classroom environment. So, the innovative nature of Web2.0 is reflected through the student centeredness and represented in their involvement in the learning process. In terms of 
students' learning, many scholars argue that Web 2.0 applications can facilitate new forms of collaborative knowledge construction, communication, identity work (Greenhow, 2011; Greenhow \& Li, 2012).

\section{Theoretical Framework}

Connecting to the focus of this study, the sociocultural theory of learning provides a solid theoretical base for the integration of web applications and teaching. It promotes a collaborative learning model through social interaction, which is not the only major advantage that web 2.0 applications embrace but a practical and theoretical basis for the field of language and literature teaching. Sociocultural theory can be traced back to the work of Vygotsky (1962), as well as later theoreticians (Wertsch, 1991, 1998), who define learning as being "embedded within social events and occurring as a child interacts with people, objects, and events in the environment" (Kublin, Wetherby, Crais, \& Prizant, 1998, p. 287). The most important argument of Vygotsky's theory is that social interactions play a fundamental role in the development of cognition. Vygotsky (1978) argues that a child's development cannot be understood by a study of the individual alone but needs an examination of the external social world in which that individual life has developed. He also concludes that every function in a child's cultural development appears both on the social (between people) and individual (inside the child) level (Vygotsky, 1978). Through participation in activities that require cognitive and communicative functions, children are drawn into the use of these functions in ways that nurture and scaffold them (Tharp \& Gallimore, 1988, pp. 6-7).

The child gradually masters an action that is qualified with cultural meaning, after many experiences of supported expression. The act has passed through the zone of proximal development ZPD during which the adult has educated the child in its use. Language learning is a socially constructed process where individuals learn the language and approach their ZPD through the negotiation, interaction and meditation with others within the community of practices (Lantolf \& Thorne, 2007). Some researchers (Gutiérrez, Baquedano-Lopez, \& Tejeda, 1999; Moje et al., 2004) have suggested that educators need to create opportunities for students to connect their formal (school) and informal (home) learning environments by incorporating students' prior knowledge and experience, as well as current literacy practices into the school curriculum. Besides the language learning field, the sociocultural theory of learning also connects with Web 2.0. Theoretically, Web 2.0 seems to embody sociocultural views of knowledge as co-constructed, decentralized and accessible by and among a broad base of users (Dede, 2007). Sociocultural theories of learning value the communication of knowledge through social practices and the opportunity to engage in various communities to learn with and from others (Vygotsky, 1978). Mason and Rennie (2013) argue for four major benefits of learner-generated content that Web 2.0 provides: 1) the learners are able to actively participate in the construction of their experience, rather than passively absorbing content; 2) the content can be continually refreshed by the learners rather than requiring expert input; 3) many of the Web 2.0 applications are collaborative in nature, thus the learners develop team skills; 4) shared community spaces and inter-group communications help motivate learners to learn.

In conclusion, the sociocultural theory of learning provides insights for rethinking the roles of teachers in the Web 2.0 environment. It enables researchers to explore the Web2.0 environment from a collaborative approach. It also has the potential to allow researchers to better understand the complicated interaction between instructors and students within a Web 2.0 environment. Moreover, the sociocultural theory of learning is a bridge to connect language learning and Web 2.0 applications, which are the two major topics of the study. 


\section{Methodology}

\section{Participants}

The participants were purposively selected. For the present study, all names were changed to provide confidentiality to all participants.

The participants are:

a) Instructors who are teaching English literature in higher education.

b) The participants have all had working experience in teaching literature ranging from 5 years to 10 years, with an average experience of 6 years.

c)All of them have graduated from universities and obtained master's degrees, or higher.

\section{Participants Profile}

\section{Fatima's Educational Background and Teaching Experiences}

Based on her resume, Fatima earned her Bachelor of Arts degree in English language and Literature in the College of Art at Ha'il University in the Kingdome of Saudi Arabia in 2007. Following that, Fatima went to a university in the north United States and continued her education by pursuing a Master of Arts degree in, English Literature from 2010 to 2013. She began to teach English courses in 2007 in Ha'il University once she graduated and got Bachelor degree as her GPA is 3.8. In 2013, she went back to Saudi Arabia and worked as an instructor in the English Department until the present.

With her growing interest in teaching literature, she began to study and obtain more and more knowledge and pedagogical skills through continuous professional development opportunities. She explained that "I've had language acquisition courses, linguistics courses and methodology courses" (Interview, 7/2/2019). As an instructor since 2013in Ha'il University, she taught undergraduate courses including Shakespeare, The Rise of the Novel, Appreciating Drama, 19th Century Novel, Romantic Poetry, etc.

\section{Salma's Educational Background and Teaching Experiences}

Salma is a female in her 30s. She received her Bachelor degree in Arts in English language and literature at Yarmouk University in Jordan in 2003. Three years later, Salma obtained her Master of Arts degree in English literature at another university in Jordan. Salma had 6 years of experience in teaching grades 7-12 Englis in public schools since she started her teaching career as a high school teacher in 2003. Until 2009, she had been a classroom teacher, and mentor teacher in nine different high schools in different cities in Jordan. After that, she moved with her family to Saudi Arabia. Since 2009, she has been an instructor in the English Department teaching different courses. With many years of teaching experiences, Salma was dedicated to sharing her teaching experience with students so that they would be able to enjoy a quality education:

As I have progressed in my career my major goal has been to return to the career a portion of what I have received. Over the years I have been instructed, inspired, encouraged and mentored by many fine and talented teachers, and I feel a very strong obligation to share with others. It is both a responsibility and pleasure to support my students (Salma's Resume, p.1). Salma's passion toward her career in teaching was evident in the above excerpt. As a language teacher for many years, her teaching philosophy also influenced her

Teaching practice. Salma believed in teaching while providing an enjoyable learning experience for students, as she explained her primary goal as a teacher "has been to share 
with students the joy and excitement of learning another language's literature and to help them develop the skills to do so competently" (Salma's Resume, p. 1). She particularly stressed how important it was for students to achieve their competency in learning a foreign language' literature. Being inspired by many teachers and mentors that she worked with, Salma was longing to share her knowledge and experience to her students.

\section{Noor's Educational Background and Teaching Experiences}

Noor is a female in mid 50s. She got her Bachelor with major in English Literature at the University of Jordan. With her interest in being a language teacher, she continued her study and earned a Master of English Literature at University of Jordan in August 1995. Noor also obtained a $\mathrm{PhD}$ in English literature at the same university in in August 2005 (Noor's Resume, p. 1). As an English teacher for over 25 years, Noor taught in various K-12 school settings. From August 1989 to June 1996, Noor taught at an elementary school in a major city in the south of Jordan. From September 1997 to June 1998, she taught at a high school in the same area. Switched to another high school in the same city in 2013, she moved to Saudi Arabia and continued her teaching career as an assistant professor in the English Department in Ha'il University until present. As an experienced teacher, Noor described several keywords in her teaching philosophy as student centered, standard-based, experiential learning, and educational technology:

I am a teacher who cares about her students and their achievement. I plan standards-aligned lessons that include experiential learning. I am highly engaged in professional development activities, both as a teacher /mentor and a lifelong learner. My educational technology skills are up to date. I positively contribute to my university community through active participation on committees (Noor's Resume, p. 1).

Her resume clearly showed that Noor valued the importance of standards-based lesson plans and experiential learning in teaching literature. She also declared that she had concurrent technology skills that could facilitate her teaching. It was also worth noting how she believed that she was proficient in using technology in her teaching practice with the continuous professional development she had.

Throughout her interviews, Noor's dedication to teaching, intensive experiences and work with both elementary and secondary, and a passion toward teaching were always notable and impressive. To her, learning a foreign language was just as important as learning math and reading because an educated person needed the ability of understanding other people and culture by learning their language.

Using her own experiences as a teacher of English, Noor shared valuable knowledge and expertise in teaching. She further explained her motivation of being a teacher and then an assistant professor:

The motivation for me is more important than money. I think, helping students and feeling like I have some expertise that I can share with them and when I look at the faces of the students I'm working with and I see the light bulb go off. It just makes me feel very happy because in my heart, I'm a teacher. Oh, and there's another reason, too... it keeps me fully abreast of what's happening. Because it's what I do, I have to read, I have to know, I have to learn, I have to grow. I have to continually understand what the research is, so it keeps me growing as a professional teacher. So, this is another reason, because I feel like to stay on top 
of my game, I have to continually learn. If you are a language teacher, you have to continually learn and grow (Interview, 2/1/2019).

\section{Zainab Educational Background and Teaching Experiences}

Zainab is an instructor in her late 30s. She studied English language and literature from 1999 and receive her Bachelor of Arts degree at a university in the Kingdome of Saudi Arabia in June 2003. From 2003 to 2005, she was hired as an English language teacher at the college where she finished her undergraduate studies. Keeping her career path in education, she then took a job at a major private education corporation as the principal assistant and English teacher for two years from 2005 to 2007. Accepted by Southeast Missouri State University, Cape Girardeau, USA, she continued her education in pursuing a Master of Arts degree in English Literature. (Zainab Resume, p. 1). Zainab also has various experiences in teaching ESL as a weekly volunteer in the United States. After she finished her study, she returned to KSA. She has taught English courses including literature courses since 2011.

\section{Instrument and Procedures}

The primary data sources for this qualitative study consist of data collected from the interviews, observations of instructors' teaching practices and instructors' self-developed documents (curriculum, lesson plans, assignments).

\section{Observations}

Two observations for each of the four participants were conducted based on their availability. An observation protocol was adopted to record and document the issues researcher had noticed regarding their discussions on and actual use of Web applications in literature teaching. Detailed time, duration, and frequency of observations were discussed with individual instructor based on their availability. Generally, each observation covered a period ranging from 50 to 60 minutes. The researcher gathered notes by conducting an observation as an observer.

\section{The Semi-structured Interviews}

Three in-depth semi-structured interviews were conducted for each of the participants from January 2019 to May 2019. The first interview was conducted at the beginning of the semester, the second interview was conducted in the middle of the semester, and the third interview was carried out as a follow-up to clarify concerns and questions with participants after the initial analysis. On the other hand, the interview questions were sent to an expert with an experience as qualitative researcher in the area of education and research in higher education to review and to provide comments about the questions' relevance and content and construct validity.

\section{Data Analysis}

In the first step, data collected from the instructors' interviews and observation was analysed for each case (each instructor). Therefore, the analysis of interview transcripts based on an inductive approach geared to identify patterns in the data using thematic codes. For each response, each question's key points were identified. Then proceed to code data into categories. Saldaña (2016, p. 3) defines coding in qualitative inquiry as: "a word or short phrase that symbolically assigns a summative, salient, essence-capturing, and/or evocative attribute for a portion of language-based or visual data". Then researcher decided to analyse each question across all responses to identify categories in that particular area of the participant' experience. Researcher then further analysed all the categories to identify major themes in the participants' overall experience. Next, all the categories were examined to 
identify key themes in the participants' experience. As Marshall and Rossman, (2016, p. 114) contend, "Identifying salient themes, recurring ideas or language, and patterns of belief that link people and settings together is the most intellectually challenging phase of the analysis and one that can integrate the entire endeavor". According to Braun and Clarke (2006), the term "thematic analysis" refers to the "method of identifying, analysing and reporting patterns (or themes) within data." Open coding will be used in this step, where every passage of the interview will be studied to determine exactly what has been said and to label each passage with an adequate code. By comparing different parts of the interview, the consistency of the interview as a whole was examined. Categories of coding or general themes emerged, based on the analysis for each of the four cases. By summarizing categories and finding consensus on the interpretation of different fragments, researcher was able to develop initial codes and achieve a basic understanding of each case. In the second step, axial coding will be used to compare fragments from different cases, focusing on the same theme or the same code. In so doing, some codes were combined and refined with other codes, forming a pattern. The constant comparative method was adopted (Corbin \& Strauss, 2008) for data analysis, which enabled researcher to look for similarities and differences within each case and across the four cases (Corbin \& Strauss, 2008).

\section{Results}

Regarding the teaching practice of using Web applications in teaching literature, four instructors showed an increasing usage trend on the level of integration. Specially, the overall usage of Web applications in four different cases ranges from Fatima's no usage, to Salma's $15 \%$, then to Noor's $30 \%$, and finally to Zainab's $40 \%$. Figure 1 demonstrates the increasing usage trend among the four individual participants based on the estimated percentage of Web applications usage in their literature courses.

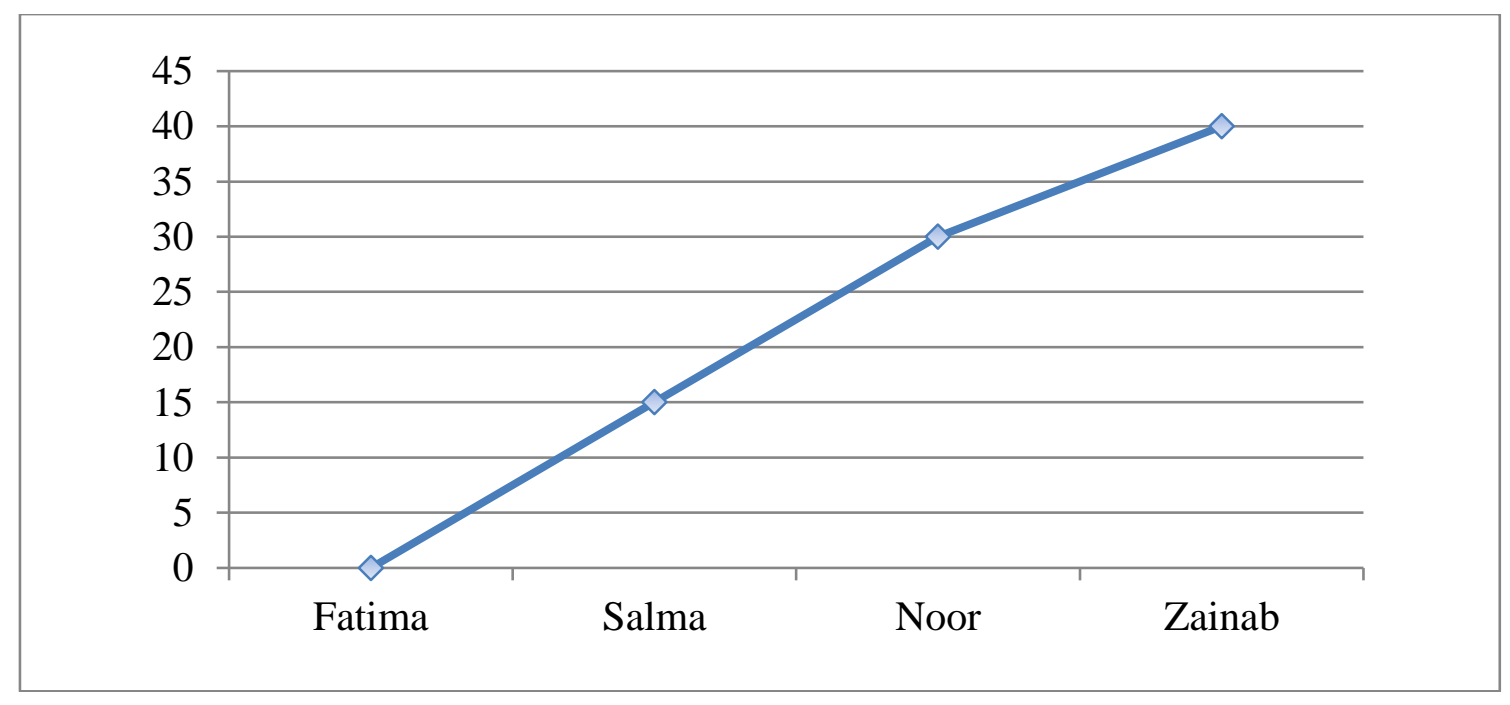

Figure 1: Web Application Usage Trend

\section{Observations}

Below are excerpts summarized from observation notes for the four cases.

Fatima's Case

It was a hot afternoon on April 19th, 2019. I was observing Fatima's The Rise of the Novel's class. Students were a little bit sleepy; some students were walking very slowly towards their seats while some of them were yawning. Fatima came into the classroom with a slight smile 
on her face, "So we want to begin. It is after lunch. I want to talk about rubrics...I want to have you create a rubric". On the blackboard, she wrote down the agenda for the class and drew a $4 \times 5$ table. The agenda included: " 1.10 minutes' introduction of rubric; 2.10 minutes' group work; 3. 15 minutes' whole class sharing; 4.10 minutes debriefing". She then began to explain the agenda items one by one by stating the expectations and tasks that participants needed to finish. While she explained everything step-by-step in the agenda, she thought aloud and informed the participants her own thinking behind each step.

She prepared markers and coloured papers for the upcoming activity. She walked around the classroom distributing the materials, while explaining what she wanted each individual group to do. Fatima explained the detailed schedule of this class to the participants; 5 minutes for introduction, 10 minutes for each group to work on the creation of the rubric, 3 minutes for each group to share, and in the end, 10 minutes to reflect what had been done. After the introduction, she asked the very first question "Do you have any questions, so far?" It was all silent in the classroom. Fatima then explained that the goal of the task was to discuss within each group the main elements of a novel.

Each group only had one minute to chat. "Plot, setting, characters", I heard many words spreading from the participants. Some participants were writing down the list of elements they discussed. When the time was up, Fatima went back to the front of the room and asked the participants to share the results. While listening to the answers, she wrote down each word the participants came up with (narration, plot, theme, point of view, narrator, Tone, subplot, setting, and character). Using all the words, she began to think aloud and tell the participants what words she could evaluate and what words she needed to delete. Finally, she chose plot, theme, setting, point of view and character. She then asked the five individual groups to choose one word from the list. All participants were discussing while one group was picking up the word. Each group was required to write down a detailed description about the word the chose. With the detailed instruction, each group discussed the descriptions that they wanted to write. All participants were engaged in conversations about their topic. Some participants wrote down the words they discussed on the paper that Fatima had given each group.

Fatima walked from one group to another, checking the progress and making sure everyone was on task. She also distributed colored papers and tape to each group. Each group had a different colored paper with tape on it. Participants wrote their descriptions on the colored paper and taped it in the $4 \times 5$ table on the blackboard. Fatima communicated with each group, discussing their descriptions and encouraging conversations among group members. After about ten minutes, all groups finished writing their descriptions and taped them on the blackboard. Based on their results, Fatima elaborated on the main elements of a novel. (Observation note, 17/2/2019).

\section{Salma's Case}

February 20th, 2019. I observed Salma's class because she was going to give an introduction to their Wiki from 9:45am to 10am.

It was a regular classroom with a projector in the middle of the room and screen showing the topic "Introduction to Our Wiki". Salma stood in the front of the classroom, already started her introduction. Salma started to talk about the home page of the Wiki site. She first explained that there was a Wiki for Shakespeare course. Salma first explained the above information. After that, Salma began to walk through every component on Shakespeare Wiki. 
She first opened the Agenda page and explained the tentative agenda for each week, introducing the topics, activities, and assignments from the beginning to the end of the semester. Week one was about Introduction to the Renaissance/ Medieval. Weeks two, three, and four reviewed Elizabethan Theatres, kinds of plays, Background of drama as a genre, influences that Shakespeare added to English literature. Weeks five, six, seven and eight focused on Hamlet. Weeks nine, ten, eleven and twelve discussed Macbeth. Weeks thirteenth, fourteenth, and fifteenth introduced Merchant of Venice. After explaining the details for each week, Salma briefly went through all the remaining components of Shakespeare's Wiki by clicking on different links for different sections in order to give a general idea of what resources were available and where they were located in the Wiki. She used about 4 minutes in showcasing all other components of the Wiki. She particularly emphasized the newly added "discussion" feature on the Wiki. She encouraged students to share their thoughts and suggestions about the readings posted on the Wiki. The entire introduction lasted about 15 minutes.

Students didn't ask any question regarding the organization and content of the Wiki (Observation notes, 20/2/2019).

\section{Noor's Case}

My classroom observation on Noor's class provides a snapshot how she used Twitter as part of her instruction.

March 25th, 2019. I observed Noor's class at around 1:00pm time. The goal of this class was to discuss the figurative language of the poem "Ulysses". After students sat down on their seats, Noor began the lesson by first showing her first slide of the lecture. "Essential Question: What Are the Figures of Speech Used in the Poem "Ulysses"?" Pulling up her Twitter account on the screen that connected to her laptop using a projector, Noor encouraged students to tweet a short answer to the above question after class. One student tweeted "The narrator describes himself as "roaming with a hungry heart," which is a metaphor!" and another one tweeted "The poem has a simile in the line "To follow knowledge like a sinking star,"!" (See Figure 6.3 Tweets about Ulysses) 


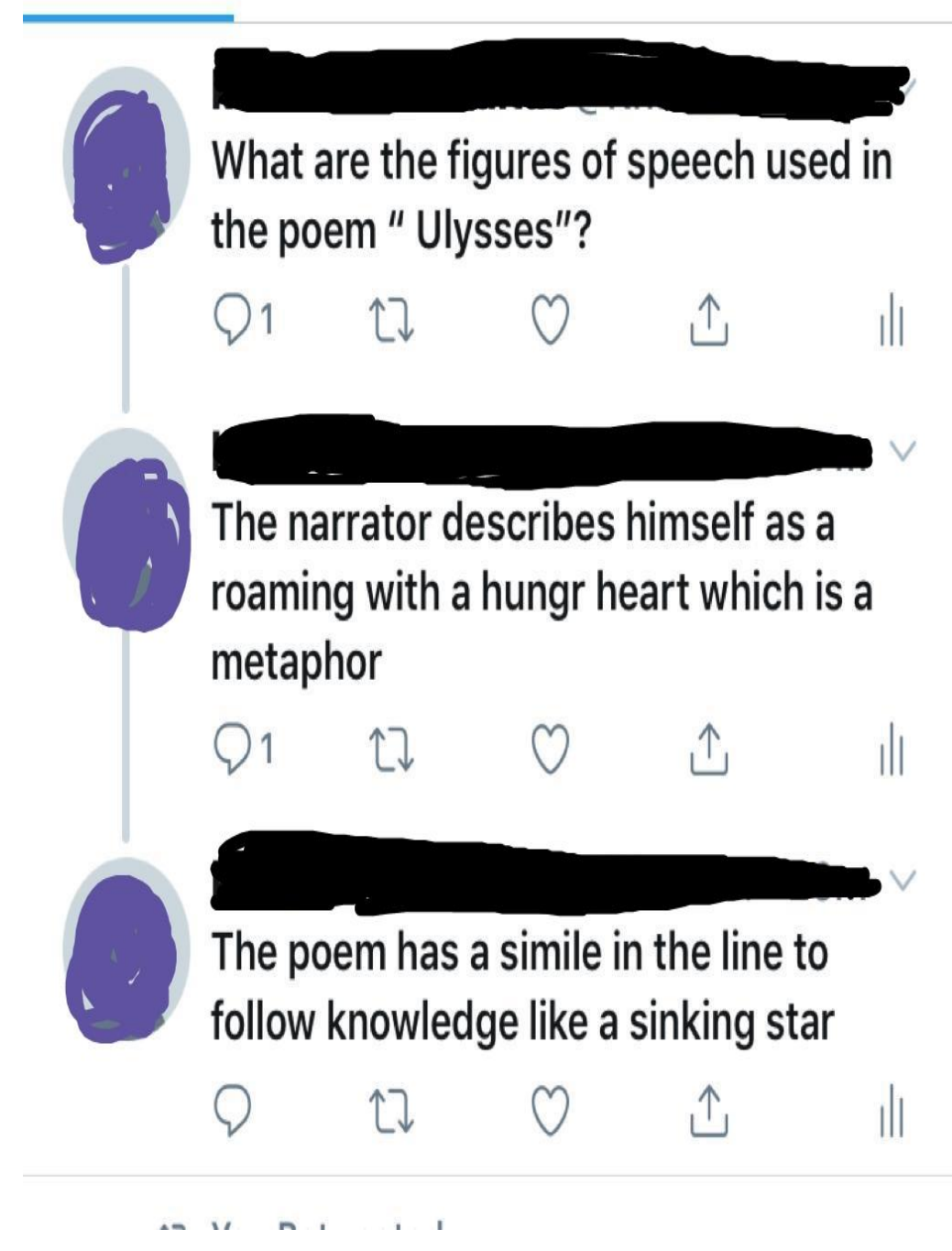

Figure 2: Tweets about Ulysses

In the meanwhile, Noor also explained to the students about possible risks of using Twitter including presenting personal ideas in the public virtual space that could be seen by people all around the world. She suggested that students who didn't want others to identify them on Twitter could create a fake account using unidentifiable Twitter user name and email account. Clearly, she had concerns about student's privacy when using Twitter.

Noor continued discussing the students' tweets then she changed to the second slide with two sets of questions on it "Highlight the significance of James Joyce's Ulysses as a major work of modernist writing?" Noor then asked students to respond to these questions by writing down their ideas on sticky notes. She spent 10 minutes to do this activity and students were required to write only one thing per sticky note. She constantly checked for comprehension of all students by asking whether they understood what they were supposed to do (Observation Notes, 25/3/2019).

\section{Zainab's Case}

I selected one scenario where Zainab was showing the uploaded PowerPoint that one of the students made to ask for another students' feedback. April 15th, 2019. Around 2pm in the afternoon, Zainab begins her lecture on providing feedback for students' Power Points. Her instructional goal is to review students' works and assess whether they provide 
comprehensive analysis to the novel Heart of Darkness written by Joseph Conrad. Zainab starts the lesson by logging in her Dropbox account and showed one of the students' Power Point about through the projector. Everyone looked at the big screen to review the PowerPoint while the student who created the PowerPoint was explaining her ideas. The student's presentation was about the structures of the novella and why Heart of Darkness is structured into three parts, and how the organization of the storytelling is significant... Then Zainab led the discussion and engaged students to discuss about the PowerPoint. Students were actively involved in the discussion. (Observation Notes, 15/4/2019).

\section{Discussion}

It is noted that, although Fatima held strong beliefs in the integration of Web applications, she didn't actually use any Web applications. However, she did report about $8 \%$ of usage for other technology (e.g. PowerPoint). Salma and Noor used the programs Wiki and Twitter. The Wiki was used for the purpose of sharing resources and collecting some reading responses (not a mandatory task though) from students and Twitter was used with the goal of enhancing communication and ideas exchange. Salma and Noor's usage of Web applications differed in a noticeable way. Salma claimed a $15 \%$ of Web applications usage and only used the Wiki and Twitter. She didn't put much emphasis on advocating the adoption of these Web applications, nor did she integrate Web applications other than the Wiki and Twitter. On the contrary, Noor mentioned $25 \%$ to $30 \%$ Web applications usage and embedded the use of Web applications in a well-designed and purposeful approach to enhance the communication among students. She tried to merge different Web applications (the Wiki, Twitter, Answer Garden) together to compare the different uses of certain Web applications with a careful plan. By clearly making the connections between Twitter, the Wiki, and sticky note activity, Noor demonstrated her expertise in planning and delivering instructions from which her beliefs in purposeful integration of Web applications and teaching literature could clearly be seen. Nonetheless, both Salma and Noor didn't fully bring all the potentials of Web applications into teaching. For example, they didn't embrace the benefit that the Wiki could have on collaboration and opportunity for peer review (Mak \& Coniam, 2008; Cabiness, \& Donovan, \& Green, 2013; Dvoretskaya, \& Dvoretsky , 2016). However, they indicated that the main reason for the failure of the Wiki's communication and collaboration was because students were difficult to be motivated or even reluctant to share their thoughts on the Wiki. Zainab stated $30 \%$ to $40 \%$ of Web applications usage and adopted Facebook, Animoto, YouTube, Google Drive, and Dropbox without pre-planning. According to Zainab, Dropbox and Google Drive were widely used by instructors and students due to its benefits in file sharing, reducing the physical distance, and enhancing communication and connection within the group. Therefore, Web applications became "essential" (Interview, 5/5/2019) even though it was not originally planned to be integrated. Facebook was used by students and instructors to post pictures and videos of their projects and works due to its easy and instantaneous feature. YouTube was also adopted to post short video clips of students' participations and further reflections. By incorporating a variety of Web applications in her teaching, Zainab clearly demonstrated her passion and enthusiasm on the integration of Web applications and teaching literature. After discussing the teaching practice of four instructors related to Web applications integration, their beliefs and teaching practice are analysed and the themes emerged from the comparison are presented in the following paragraphs.

Overall, all four-instructor held strong beliefs about the importance of Web applications in teaching English literature. On the other hand, all four participants expressed explicitly that learning a foreign language's literature would be beneficial in many aspects including: broadening one's view, doubling one's knowledge, increasing global competency, and 
helping people better understand other culture (Participants Interviews). It is important to note that, even though the degree of Web applications integration varied from case to case, all four participants cared about their students and always tried to provide positive learning experiences. For example, all four participants emphasized the real-life connection and authenticity. During the observations, all four participants tried to engage students with meaningful tasks. (Observation Notes). Specifically, Salma and Noor explained the Wiki and encouraged students to share their ideas; Zainab adopted a variety of Web applications to build the connection between the material itself and her instruction.

Furthermore, the findings from four cases depicts a mixed result in that some instructors' beliefs about the integration of Web applications and teaching literature differed from their teaching practices, while others' beliefs aligned with their practices closely. By analyzing all the data from four participants to answer the research question, three out of the four instructors (Salma, Noor, and Zainab)' beliefs aligned with their teaching while one instructor's (Fatima) beliefs differed from her teaching practice about the integration of Web applications and teaching literature. Salma's beliefs about the integration of Web applications and teaching literature were aligned with her teaching practice in literature courses. In her teaching practice, Salma only used the Wiki as a resource center for students to access related materials. Salma didn't push students too much to share their ideas. She showed an indifferent attitude toward Twitter and wasn't actively involved in the tweeting process. This limited usage of Web applications in teaching matched with Salma's beliefs about the integration of Web applications. She took a rather neutral way to acknowledge Web applications, valuing its popularity and some educational benefits in teaching literature while believing in a gradual process for Web applications to be integrated with literature courses. Because of the wide acceptance of Web applications among students, Salma believed that Web applications could play a role in teaching literature and instructors should be aware of various Web applications to keep up with their students. She valued Web applications based on its advantages in facilitating communication. Although she understood and thought highly of the collaboration and communication feature of Web applications, she considered Web application as just one of the tools that instructors could use.

Noor's case was overall consistent in that her beliefs in teaching literature and the integration of Web applications were all aligned together and enacted in her teaching practices. She perceived herself as an open-minded instructor who was willing to learn new skills and knowledge to make her teaching better. This kind of belief played an important role in forming her beliefs about the integration of Web applications and teaching literature. She chose a pragmatic approach when conceptualizing Web applications and its benefits in teaching literature. She showed a welcoming attitude toward Web applications and she felt that she needs to adopt Web applications when she found the meaningful purposes of using it. She realized the integration of Web applications could not be stopped, thus, the better way to deal with it was to learn to use them and design purposeful plans to make them effective.

Zainab's beliefs about the integration of Web applications and teaching literature also aligned with her teaching practice. She paid special attention on the values of spontaneous Web applications integration in literature courses. She believed that Web applications could be beneficial in connecting students and extending learning beyond the classroom. In her teaching practice, although Zainab didn't particularly plan deliberately for Web applications integration, a variety of Web applications were used formally and informally throughout the course. She adopted Google Drive and Dropbox to share resources with students and utilized Facebook for building personal connections with students. Students' frequent use of 
Web applications, as Zainab reported, would help them to share their beliefs, influence each other's practice, and eventually build a support community in literature learning. Zainab's active participation in using Web applications informally was beneficial in connecting with students and building positive relationship between her and them. Contrary to the previous three cases, Fatima's case was unique because of the conflicting facts that while she held strong beliefs in the integration of Web applications and teaching literature, she didn't use any Web applications in her literature courses. Fatima was enthusiastic about trying new technology in teaching literature. However, due to the fact that she had unclear conceptualizations of Web applications and technology, she was unable to adopt Web applications as much as she wanted to. This dilemma also indicates that the integration of Web applications depends on many factors, some of which may be outside of the instructor's control. Therefore, even if instructors have strong beliefs in using Web applications in teaching literature, they need to overcome many obstacles beyond the pedagogical level of how to use Web applications, such as lack of tech support and lack of internet access, individual differences among participants and university policies and rules. Fatima's case is the only one that beliefs and practice were not matched due to the first-order and second-order barriers (Ertmer et al., 2001; Fatemi \& Mellati., 2013). This special case calls for more research on exploring the impact that first-order and second-order barriers have on instructors' beliefs (Ertmer et al., 2001; Larenas, Hernandez.,2015).

Findings from the cases where instructors' beliefs and practice aligned reinforced the claim about instructors' beliefs played an important role in instructional decision making in the teaching practice (Smith, 2005). However, more empirical research is needed to further unravel the complicated relationship between teacher beliefs and teaching practices.

Synthesizing from four individual cases, two themes can be found in relation to my first research question: 1) participants used the terms Web applications and technology interchangeably; 2) participants believed that Web applications are beneficial in facilitating collaboration and communication in teaching literature.

It is clear that participants used the terms web applications and technology interchangeably. Based on the four individual cases that were presented from Chapter Four to Seven, three instructors (Fatima, Salma, and Zainab) used the term Web applications interchangeably with the term technology. They all defined Web applications in a broad way that, to some degree, is difficult to differentiate with the term technology. Only one instructor, Noor, showed a relatively better understanding of the term Web applications. Fatima conceptualized the term Web applications in a broad way that could include all of the things that one can charge and plug in and connect to using a wireless internet connection, such as texting, Facebook and Twitter, and also reported her observations regarding the prevalent use of Web applications among her students (Interview, 7/2/2019). Fatima's definition of Web applications includes everything that can be used with a wireless Internet connection, which is not clear to differentiate with the term technology. In her interviews, Fatima sometimes used the two terms, Web applications and technology, interchangeably without making a distinction. Similar to Fatima, Salma also defined Web applications in her interviews as a broad concept that included tools and applications more than Facebook and Twitter (1/1/2019). Zainab also considered Web applications as a broad term that people couldn't avoid using in today's world. Using her own experiences with various technology (computers, smartphone, I Pad) and Web applications (Facebook, Twitter, Skype, LinkedIn, Animoto), Zainab was absolutely aware of different Web applications and had been using them frequently for her personal purposes. However, Zainab seemed to interchangeably use the two terms, technology and 
Web applications. She perceived that Web applications and technology couldn't be differentiated easily by drawing a clear line between the two. Each time Zainab talked about Web applications, she connected it to things such as computers, IPads, and smartphones which were technology devices used to access Web applications. Although Zainab showed a rather unclear conceptualization of Web applications, she perceived that Web applications "like an invisible net that really connected us" (Interview, 3/1/2019).

Noor, on the other hand, had a relatively clearer conceptualization towards Web applications. She mentioned that "Web applications are the use of technology in such a way that people can interact with one another regardless of whether they are next to each other" (Interview, 2/1/2019). Noor defined that Web applications as a kind of technology that served as reducing the physical distance among people. With the emphasis on facilitating communication and interaction among people, Noor pointed out one of the distinguishing features of Web applications. Moreover, Noor conceptualized Web applications within the context of teaching literature and concluded that Web applications were effective when used in teaching literature. Although Noor expressed a better understanding about Web applications, the majority of the instructors demonstrated an ambiguous perception about Web applications and their core features, which may impact their practice of the integration of Web applications and teaching literature.

In addition to that, participants believed that web applications are beneficial in facilitating collaboration and communication in teaching literature. Comparing all four instructors' views about the integration of Web applications and teaching literature, a major potential benefit that all participants agreed upon is that Web applications can facilitate collaboration and communication in teaching literature. Fatima summarized the benefits of using Web applications in teaching literature as: 1) Web applications could be used as "back channel option of communicating" in literature discussion, especially in "a panel discussion or something and you've got these sort of multiple conversations going on" (Interview, 15/4/2019); 2) sharing knowledge and information using "Wiki" and "Google Doc" (Interview, 20/3/2019); 3) extending the learning "outside of classroom" (Interview, 2/5/2019); and 4) Web applications could contribute to a more "enriched discussion because they [students] were bringing up authentic materials" (Interview, 20/4/2019). All these benefits validate the argument that Web applications are beneficial in enhancing communication and collaboration.

Salma valued the instantaneous and collaborative feature of Web applications, which supported the real-life communication in teaching literature. The ability to connect with people who speak the target language instantly using Web applications could help learners use foreign language in meaningful and authentic practices, get better understanding of the target culture, thus, enhance the literature learning. By acknowledging the popularity of Web applications in young students and even many instructors, Salma considered it was valuable to use Web applications in teaching literature. With the advantages of Web applications, Salma believed that it could easily motivate students and thus facilitate their collaboration and communication.

Noor, in her mind, emphasized the value of Web applications in teaching literature because both Web applications and teaching literature relied heavily upon communication. She stated that the integration of Web applications and teaching literature would be effective if Web applications were adopted to enhance communication. Zainab also believed that Web applications were used by everyone to a natural degree that it became a major component of 
student's life nowadays which couldn't be excluded. Widely adopted by everyone, Web applications are indeed "an invisible net" that connect different people together (Interview, 20/4/2019).

The four instructors clearly stated the benefits that Web applications could add to teaching literature, including reducing physical distance, enhancing communication, facilitating collaboration, engaging and motivating learners and building a "community of practice".

Although the beliefs varied from case to case, the four instructors overall showed a positive attitude towards the adoption of Web applications in teaching literature. As far as the integration of Web applications and teaching literature is concerned, four instructors differed in their beliefs, ranging from an indifferent view (Salma), to a pragmatic one (Noor), to a spontaneous one (Zainab), and to a conflicting one (Fatima). More specifically, Salma showed an indifferent attitude towards the usage of Web applications when teaching literature and believed that Web applications are only one of the tools that literature instructors needed to be aware of. Salma only used the Wiki and Twitter as department requirement and didn't fully integrate the Web applications with more explicit instruction and various purposes. Noor always tried to find a pragmatic way of integrating Web applications with a meaningful purpose in real life situation. A good case in point is the scenario where Noor integrated Twitter, and Sticky Note activity together to engage students to share their ideas about the significance of James Joyce's Ulysses as a major work of modernist writing. Zainab demonstrated her beliefs about integrating Web applications in teaching literature in a spontaneous way while she adopted a variety of Web applications without a detailed plan before the semester started. Fatima held an enthusiastic attitude towards the integration of Web applications and teaching literature but didn't use any Web applications in her courses.

\section{Conclusion}

The goal of this study was to explore differences and similarities between literature instructors' beliefs and actual practices of integrating Web applications in literature courses. The results showed that a majority of instructors' beliefs aligned well with their practices about integrating Web applications with teaching literature while one participant's beliefs conflicted with her teaching practices. Result also supported the argument that instructor belief plays an important role in instructional decision making in the teaching practice while sometimes differed with their classroom practice. Results also revealed that the actual Web applications usage found in the four cases demonstrated positive result for the integration of Web applications. This provides evidence to support previous research results about the benefits that Web applications have in possibly connecting informal learning to the formal learning environment. On the other hand, although four individual instructors' actual use of Web applications differed from case to case, they all believed that there were many benefits as well as challenges when integrating Web applications in literature courses. Furthermore, the results demonstrated an increasing usage trend among the four individual participants based on the estimated percentage of Web applications usage in their literature courses. Nonetheless, four participants in this study seemed to only bring out a few aspects of Web applications' potential. To make the best of Web applications, more research is needed in identifying best practices of various Web applications in teaching literature and explaining complicated instructors beliefs about the effectiveness of Web applications in teaching literature. 


\section{References}

Abdi, H., \& Asadi, B. (2015). A Synopsis of Researches on Teachers' and Students' Beliefs about Language Learning. International Journal on Studies in English Language and Literature (IJSELL), 3(4), 104-114.

Aghaei, S., Nematbakhsh, M. A., \& Farsani, H. K. (2012). Evolution of The World WideWeb: From Web 1.0 To Web 4.0. International Journal of Web \& Semantic Technology (IJWesT), 3(1).

Alharbi, H. (2015). Improving students' English speaking proficiency in Saudi public schools. International Journal of Instruction, 8 (1), 105-116.

Al-Asmari, A. \& Khan, M. (2014). E-learning in Saudi Arabia: Past, Present and Future. Near and Middle Eastern Journal of Research in Education. 1 (2).

Alhamdi, N. (2014). English Speaking Learning Barriers in Saudi Arabia: A Case Study of Taibah University. Arab World English Journal, 5(2), 38-53.

Alrashidi, O., \& Phan, H. (2015). Education context and English teaching and learning in the Kingdom of Saudi Arabia: An overview. English Language Teaching, 8(5), 33-44.

Al-Zyoud, K., \& Muhammad,K. (2012). The use of YouTube in teaching English literature: The Case of Al-Majma'ah Community College, Al-Majma'ah University, International Journal of Linguistics, 4(4),4-5.

Amiryousefi, M. (2015). Iranian EFL Teachers and Learners' Beliefs about Vocabulary Learning and Teaching. International Journal of Research Studies in Language Learning, 4(4), 29-40. https://doi.org/10.5861/ijrsll.2015.1016

Barassi, V. and E. Treré (2012) 'Does Web 3.0 Come After Web 2.0? Deconstructing Theoretical Assumptions Through Practice'. New Media \& Society. 14(8): 1269-1285.

Bower, M. (2015). Deriving a typology of Web 2.0 learning technologies. 1-13, EDUCAUSE.edu. doi:10.1111/bjet.12344.

Braun, V. \& Clarke, V. (2006). Using thematic analysis in psychology. Qualitative Research in Psychology, 3(2), pp. 77-101.

Brown, S. A. (2012). Seeing Web 2.0 in context: A study of academic perceptions. Internet and Higher Education, 15, 50-57.

Cabiness, C., Donovan, L. \& Green, T. (2013). Integrating wikis in the support and practice of historical analysis skills. Tech Trends: Linking Research \& Practice to Improve Learning, 57(6), 38-48.

Caverlee, J., \& Webb, S. (2008, April). A large-scale study of MySpace: Observations and implication for online social networks. Paper presented at the International Conference on Weblogs and Social Media, Seattle, WA. Retrieved August 28, 2019, from http://faculty.cs.tamu.edu/caverlee/pubs/caverlee08alarge.pdf

Celik, I., Sahin, I., \& Akturk, A. (2014). Analysis of the relations among the components of technological pedagogical and content knowledge (TPACK): A structural equation model. Journal of Educational Computing Research, 51(1), 1-22.

Corbin, J. M., \& Strauss, A. L. (2008). Basics of qualitative research (3rd ed.). London, UK: Sage.

Coutinho, C. (2009). E-learning 2.0: challenges for lifelong learning. In I. Gibson et al.(Eds.), Proceedings of Society for Information Technology \& Teacher Education International Conference 2009 (pp. 2768-2773). Chesapeake, VA: AACE. Retrieved from http://www.editlib.org/p/31058

Daher, T., \& Lazarevic, B. (2014). Emerging instructional technologies: Exploring the extent of faculty use of Web 2.0 tools at a mid-western community college. Tech trends:Linking Research \& Practice to Improve Learning, 58(6), 42-50. doi:10.1007/s11528- 014-0802-1. 
Delgado, A. J., Wardlow, L., McKnight, K., \& O’Malley, K. (2015). Educational technology: A review of the integration, resources, and effectiveness of technology in K-12 classrooms. Journal of Information Technology Educa-tion: Research, 14, 397-416. Retrieved from http://www.jite.org/documents/Vol14/JITEv14ResearchP397416Delgado1829.pdf.

Downes, S. (2004). Educational blogging. Educause Review, 39, 14-27.

Downes, S. (2005). Are the Basics of Instructional Design Changing? Retrieved 01/04/08, from http://www.downes.ca/cgi-bin/page.cgi?post=6

Downes, S. (2005). E-learning 2.0. E-Learning Magazine, 2005(10), 1.

Dron, J., \& Anderson, T. (2014). Teaching crowds: Learning and social media. Athabasca,Alberta, Canada: Athabasca University Press.

Dvoretskaya, E. \& Dvoretsky,D.(2016) Wikis in Integrating the Study of Culture and English Language Learning from t: https://www.researchgate.net/publication/316623032

Ertmer, P. A. (2005). Teacher pedagogical beliefs: the final frontier in our quest for technology integration? Educational Technology Research and Development, 53(4), 25-39.

Ertmer, P. A., Gopalakrishnan, S., \& Ross, E. M. (2001). Technology-using teachers: Comparing perceptions of exemplary technology use to best practice. Journal of Research on Technology in Education, 33(5), 1-26.

Farmer, J., \& Bartlett-Bragg, A. (2005). Blogs@ anywhere: High fidelity online communication. Balance, fidelity, mobility: Maintaining the momentum, 197-203.

Fatemi \& Mellati. (2013). The Relationship between Iranian ELT Instructors' Beliefs about Language Teaching and Their Practices in Real Classrooms.

FSSE. (2010, July 25). Professors' use of technology in teaching. The Chronicle of Higher Education. Retrieved on April 29, 2018, from http://chronicle.com/article/Professors-

Useof/123682/?sid=wc\&utm_source=wc\&utm_medium=enGreenhow, C. (2011). Online social networks and learning. On the Horizon, 15(1), 4-12.

Gikas, J., Grant, M. M. (2013). Mobile computing devices in higher education: Student perspectives on learning with cellphones, smartphones \& social media. Internet and Higher Education, Vol. 19, p. 18-26.

Green, L. S., Inan, F. A., \& Maushak, N. J. (2014). A case study: The role of student generated vidcasts in k-12 language learner academic language and content acquisition. Journal of Research on Technology in Education, 46(3), 297-324. doi:10.1080/15391523.2014.888295.

Greenhow, C. (2011). Online social networks and learning. On the Horizon, 15(1), 4-12.

Greenhow, C., \& Lewin, C. (2016). Social media and education: Reconceptualizing the boundaries of formal and informal learning. Learning, Media and Technology, 41(1), 6-30.

Greenhow, C. \& Li, J. (2012). Like, comment, share: Collaboration and civic engagement within social network sites. For inclusion in Mouza, C. \& Lavigne,N. (Eds.). Emerging technologies for the classroom: A learning sciences perspective. Springer.

Gustad, A. (2014). The impact of technology on literacy motivation on elementary school English language learners: Podcasting in a 4tth grade eal class. International Schools Journal, 34(1), 75-84.

Gutiérrez, K., Baquedano-Lopez, P., \& Tejeda, C. (1999). Rethinking diversity: Hybridity and hybrid language practices in the third space. Mind, Culture, \& Activity, 6(4), 286303.

Hicks, A., \& Graber, A. (2010). Shifting paradigms: Teaching, learning and web 2.0. Reference Services Review, 38(4), 621-633. 
Hussein, E. T. Al-Emami, A.H. (2016). Challenges to Teaching English Literature at the University of Hail: Instructors' Perspective. Arab World English Journal, 7(4)(1-2).

Imperatore, C. (2009). What you need to know about Web 2.0. Techniques: Connecting Education and Careers. 84(1), 20-23.

Kenny, M. A. (2015). Using Social Media in Language Teaching and Learning: Some Pedagogical and Technological Considerations. Website: http://www.onevoiceforlanguages.com/uploads/2/4/6/7/24671559/using_social_media _in_language_teaching_and_learning.pdf

Kublin, K. S., Wetherby, A. M., Crais, E. R., \& Prizant, B. M. (1989). Prelinguistic dynamic assessment: A transactional perspective. In A. M. Wetherby, S. F. Warren, \& J. Reichle (Eds.), Transitions in pre linguistic communication (pp. 285-312). Baltimore, MD: Paul H. Brookes.

Lantolf, J. P. \& S. L. Thorne (2007). Sociocultural theory and second language learning. In B. VanPatten \& J. Williams (eds.), Theories in second language acquisition. Mahwah, NJ: Lawrence Erlbaum, 201-224.

Larabee, K., Burns, M., \& McComas, J. (2014). Effects of an ipad-supported phonics intervention on decoding performance and time on-task. Journal of Behavioral Education, 23(4), 449-469. Doi: 10.1007/s10864-014-9214-8.

Li, X. (2012). The Role of Teachers' Beliefs in the Language Teaching-Learning Process. Theory and Practice in Language Studies, 2(7), 1397-1402.

Liu, I., Wu, S., \& Ko, H., (2014b). Learning reading strategies with online discussion. Journal of Educational Computing Research 50(2), 231-247. Doi:10.2190/EC.50.2.e.

Mak, B., \& Coniam, D. (2008). Using wikis to enhance and develop writing skills among secondary school students in Hong Kong. System, 36, 437-455.

Marshall, C., \& Rossman, G. B. (2016). Designing qualitative research. (6th edition) Thousand Oaks, CA: Sage.

Mason, R., \& Rennie, F. (2013). E-learning and social networking handbook: Resources for higher education (2nd ed). New York, NY: Routledge.

Matson, Susan. (2016, March). Acclimatizing Saudi Students. Language Magazine. http://languagemagazine.com/?page_id=6364

Meirink, J. A., Meijer, P. C., Verloop, N., \& Bergen, T. C. M. (2009). Understanding Teacher Learning in Secondary Education: The Relations of Teacher Activities to Changed Beliefs about Teaching and Learning. Teaching and Teacher Education, 25, 89-100. http://dx.doi.org/10.1016/j.tate.2008.07.003

Merchant, G. (2012). Unravelling the social network: theory and research. Learning, Media and Technology, 37(1), 4-19.

Moje, E. B., McIntosh-Ciechanowski, K., Kramer, K., Ellis, L., Carrillo, R., \& Collazo, T. (2004). Working toward third space in content area literacy: An examination of everyday funds of knowledge and discourse. Reading Research Quarterly, 39(1), 3871.

Moran, M., Seaman, J., \& Tinti-Kane, H. (2012). Teaching, learning, and sharing: How today's higher education faculty use social media. Boston, MA: Pearson Learning Solutions. $\quad$ Retrieved from http://www.pearsonlearningsolutions.com/educators/pearson-socialmediasurvey2011-bw.pdf.

Norton, L., Richardson, J. T. E., Hartley, J., Newstead, S., \& Mayes, J. (2005). Teachers' beliefs and intentions concerning teaching in higher education. Higher Education, 50, 537-571.

O'Reilly, T. (2012). Various Things I Have Written. Website: http://www.oreilly.com/tim/ Statistics data. (2016). Website: http://www.statista.com/topics/1164/social-networks/ 
Pellegrino, J. \& Hilton, M. (2012). Education for life and work: Developing transferable knowledge and skills in the 21st century. Washington, DC: National Research Council.

Poellhuber, B., \& Anderson, T. (2011). Distance students' readiness for social media and collaboration. The International Review of Research in Open and Distance Learning, 12(6), 102-125.

Rienties, B., Brouwer, N., Lygo-Baker, S. (2013). The effects of online professional development on teachers' beliefs and intentions towards learning facilitation and technology. Teaching and Teacher Education, 29, 122-131.

Rudd, P., \& Walker, M. (2010). Children and young people's views on Web 2.0 technologies. LGA Research Report. (ED511383).

Smith, L. K. (2005). The impact of early life history on teachers' beliefs: in-school and outof-school experiences as learners and knowers of science. Teachers and Teaching: Theory and Practice, 11(1), 5-36.

Saldaña, J. (2016). The coding manual for qualitative researchers. (3rd ed.) London, England: Sage.

Salmon, G., Ross, B., Pechenkina, E., \& Chase, A. (2015). The space for social media in structured online learning. Research in Learning Technology, 23, 28507. Retrieved from: http://dx.doi.org/10.3402/rlt.v23.28507.

Saroyan, A., \& Amundsen, C. (2001). Evaluating university teaching: Time to take stock. Assessment and Evaluation in Higher Education, 26, 337-349.

Sofi, L. (2015). Teaching English in Saudi Arabia Through the Use of Multimedia. (Unpublished Master Thesis), University of San Francisco, San Francisco.

Song, F. W. (2010). "Theorizing Web 2.0", Information, Communication \& Society, 13/2, 249-275. iTay, L., Lim, C., \& Lim, S. (2015). Differences in ICT usage across subject areas: A case of an elementary school in Singapore. Journal of Educational Computing Research, 53(1), 75-94.

Tharp, R. G., \& Gallimore, R. (1988). Rousing minds to life: Teaching, learning, and schooling in social context. Cambridge, England: Cambridge University Press.

Toetenel, L. (2014). Social networking: A collaborative open educational resource. Computer Assisted Language Learning, 27(2), 149-162.

Tian, S. W., Yu, A. Y., Vogel, D., \& Kwok, R. C. W. (2011). The impact of online social networking on learning: a social integration perspective. International Journal of Networking and Virtual Organizations, 8(3), 264-280.

Vygotsky, L.S. (1962). Thought and Language. Cambridge, MA: MIT Press.

Vygotsky, L.S. (1978). Mind in Society. Cambridge, MA: Harvard University Press.

Wertsch, J. V. (1991). Voices of the mind: A sociocultural approach to mediated action. Cambridge, MA: Harvard.

Wertsch, J. V. (1998). Mind as action. Oxford: Oxford University Press. 